\title{
RELATIVE GEOMETRIC INEQUALITIES FOR COMPACT, CONVEX SURFACES
}

\section{A. Cerdán, C. Miori, U. Schnell and S. Segura Gomis}

\begin{abstract}
We obtain relative geometric inequalities for compact, convex surfaces. In particular, we present several inequalities comparing the relative area and the relative perimeter with the maximal and minimal relative diameter. Besides considering the general problem we also consider particular cases where we can obtain sharper results: 1) the so called fencing problems in which only subdivisions into two regions of the same area are considered, 2) the subdivisions obtained by planar cuts.
\end{abstract}

Mathematics subject classification (2010): 52A40, 51M16.

Keywords and phrases: Geometric inequalities, convex surfaces, compact surfaces.

\section{REFERENCES}

[1] F. BERNSTEIN, Über die isoperimetrische Eigenschaft des Kreises auf der Kugeloberflche und in der Ebene, Math. Ann., 60 (1905), 117-136.

[2] D. Burago, Y. Burago and S. Ivanov, A Course in Metric Geometry, American Mathematical Society, 1984.

[3] A. Bieberbach, Über eine Extremaleigenschaft des Kreises, Jber. Deutsch. Math.-Vereinig, 24 (1915), 247-250.

[4] A. Cerdán, U. Schnell and S. Segura Gomis, On relative geometric inequalities, Math. Ineq. and Appl., 7, 1 (2004), 135-148

[5] A. Cerdán, C. Miori And S. Segura Gomis, On relative isodiametric inequalities, Beitrage zur Algebra und Geometrie, 45, 2 (2004), 595-605.

[6] A. CERDÁN, Comparing the relative volume with the relative inradius and the relative width, to appear in Journal of Ineq. and Appl.

[7] A. CiAnchi, On relative isoperimetric inequalities in the plane, Boll. Unione Mat. Italiana, 7, 3-B (1989), 289-325.

[8] A. Cotton, D. Freeman, A. Gnepp, T. NG, And C. Yoder, The isoperimetric problem on some singular surfaces, Journal of the Australian Mathematical Society, 78, 2 (April 2005), 167-199.

[9] M. Gromov, Metric structures for Riemannian and non-Riemannian spaces, Springer, Berlin, 2007.

[10] J. Jost, Riemannian Geometry and Geometric Analysis, Springer-Verlag, Berlin, 2002.

[11] S. MARKVORSEN, On curvature and shape: a comparison geometric survey, Exposition. Math., 13, 5 (1995), 417-432.

[12] R. Osserman, The isoperimetric inequality, Bulletin American Mathematical Society, 6 (1978), 1182-1238.

[13] C. Peri, On relative isoperimetric inequalities, Conferenze del Seminario di Matematica dell'Università di Bari, 279 (2000).

[14] L. Santaló, Sobre los sistemas completos de desigualdades entre tres elementos de una figura convexa plana, Math. Notae, 17 (1961), 82-104.

[15] R. SChNeIder, Convex bodies: the Brunn-Minkowski theory, Cambridge University Press, Cambridge, 1993.

[16] P. R. Scott, And P. W. Awyong, Inequalities for Planar Convex Sets, J. Ineq. Pure and Appl. Math., 1, 1 (6) (2000). 